\title{
Images of Conflict and Explicit Violence on Arab TV: A Visual Content Analysis of Five pan-Arab News Networks
}

\author{
By Michael D. Bruce* \\ Lindsey Conlin ${ }^{\dagger}$
}

This study employed a quantitative content analysis in order to examine the framing of visual images of conflict and violence in television news programming from five transnational satellite news channels that broadcast to/from the Arab world - Al Jazeera, Al Jazeera English, Al Arabiya, Alhurra, and BBC Arabic. Comparisons were conducted between the individual networks, and between two dimensions of network taxonomy - western (BBC Arabic, Alhurra, and Al Jazeera English) and liberal commercial (Al Jazeera and Al Arabiya). The images form 6,595 shots were examined using a five category coding scheme for conflict and violence. Results show that liberal commercial Arab networks - news outlets that broadcast from the Arab world to an international audience - displayed more conflict visuals than western networks, which broadcast from the west to an Arab audience. Violent imagery was also more explicit on liberal commercial networks. However, most of the visuals displayed on both types of Arab media did not focus on conflict at all, indicating that fear of a violent Arab media may be an over-reaction.

Keywords: Arab media, violent images, visual framing

\section{Introduction}

Historically, the Arab media has been one of the most closed media systems in the world (Hafez, 2001), and by extension, has suffered from a lack of research by media scholars. While violence and conflict have been studied under other conditions (Barnett and Reynolds, 2009), few academic research analyses have examined specifically visual content in Arab media. Previous research has shown that Al-Jazeera was more likely than CNN to cover civilian victims of violence, particularly in visual, video content (Jasperson \& ElKikhia, 2003). It follows that an analysis of images associated with Arab media outlets is necessary. Therefore, the current study will attempt to analyze how violence and conflict in routine news production are framed in visual content found in Arab media through the use of a content analysis. Visual content includes pictures and video, as contained in the various individual shots that appear in news broadcasts. When media content is framed in different ways, this changes how the issues are perceived and interpreted by audience members.

\footnotetext{
* Assistant Professor, Telecommunication \& Film Department, The University of Alabama, USA.

$\dagger$ Assistant Professor, School of Mass Communication and Journalism, The University of Southern Mississippi, USA.
} 


\section{Literature Review}

\section{Framing Theory}

According to Entman, "to frame is to select some aspects of a perceived reality and make them more salient in a communicating text, in such a way as to promote a particular problem definition, causal interpretation, moral evaluation, and/or treatment recommendation for the item described" (1993, p. 52). How journalists choose to present the news not only affects the perceived importance of stories and issues, but also the interpretation of issues by the audience and the general public (Pan \& Kosicki, 1993).

Through framing, media have the power to shape what audiences believe the overall issue to be, how important it is, and what actions should be taken in response (Entman, 1993; Gamson and Modigliani, 1989; Gitlin, 1980; Jasperson, Shah, Watts, Faber, \& Fan, 1998). This ability to change how audiences think through the presentation and emphasis of certain aspects of news is referred to as framing effects (Chong \& Druckman, 2007). Framing effects have been demonstrated in a variety of media situations, including how something as simple as word choice affects overall opinion changes (Entman, 1993; Gamson \& Modigliani, 1989; Gitlin, 1980; Jasperson et al., 1998).

Framing, then, is an organizing function for both the media and the audience. According to Norris, Kern, and Just (2003) "the essence of framing is selection to prioritize some facts, images, or developments over others, thereby, either consciously or unconsciously, promoting one particular interpretation of events" (p. 11). Herman and Chomsky (1988) state media framing plays a significant part in establishing how an event is understood.

\section{Visual Images in News}

Scholars (Fahmy, 2010; Fahmy \& Kim, 2008; Messaris, 1992, 1994; Messaris \& Abraham, 2001) have recognized that visuals operate differently from verbal narratives in the way meaning is transferred from media to the audience. Messaris has written extensively about the role of images in communication, and the differences from verbal language in the framing process. Messaris and Abraham argue that the analogical quality of images is what most clearly differentiates them from words. Analogical quality refers to the idea that images are similar to, or analogous to, the things they represent. Therefore, unlike words, visuals can be interpreted without prior familiarity or culturally based conventions. The consequences to viewers is that "images appear more natural, more closely linked to reality than words" and can cause them to ignore the fact that "all images are human-made, artificial constructions" (p. 217). This results in what Kepplinger (1991) describes as people taking images at face value.

Using visual images in media create a sense of "this event really happened and this photo is the proof of it" (Hall, 1973, p. 188). This effect has been referred to as "having-been-there" (Barthes, 1978, p. 44); "aspects of nature" or "actuality" (Hall, 1973). Even Barnhurst's definition of photojournalism - "the 
depiction of real events and the promulgation of the result to a wide audience" (Barnhurst, 1994, p. 38) - focuses on the reality, or actuality of captured events. Thus, scholars suggest that images presented through the media often appear to be free of ideological biases by appearing to capture reality (Hall, 1973; Messaris \& Abraham, 2001; Woollacott, 1982). This may explain why visual depictions are considered to be objective (Tirohl, 2000) and more believable (Graber, 1987; McLuhan \& Fiore, 1967; Pfau et al., 2008).

Framing researchers have operationalized several approaches for measuring visual frames (Matthes, 2009; Semetko \& Valkenburg, 2000). Following Entman's (1993) lead, a number of studies have focused on visual frequency and prominence as key indicators of visual framing (Fahmy, 2004; 2010; Fahmy \& Kim, 2008; Ghanem, 1997; Vujakovic, 1998). Entman's references to the importance of visual frequency and prominence are similar to Gitlin's description of framing as "persistent selection, emphasis, and exclusion" (1980, p. 7).

\section{Cross-Cultural Analysis and Arab Media}

Although few researchers have expressly studied visual framing, several scholars have examined broader media frames among Arab media. Jasperson and El-Kikhia (2003) conducted one of the first cross-cultural content studies that included Al Jazeera programming. Their qualitative framing analysis compared the use of three news frames - governance, military, and humanitarian - on CNN and Al Jazeera. Their findings revealed that CNN coverage emphasized governance and military frames, while Al Jazeera's coverage emphasized humanitarian frames. In addition, they found that $\mathrm{Al}$ Jazeera video footage emphasized collateral damage including visuals of dead and wounded civilians.

Aday, Livingston, and Hebert (2005) also conducted a cross-cultural analysis of television news coverage. They compared news coverage of the 2003 Iraq war from Al Jazeera, ABC, CBS, NBC, and Fox News. The researchers examined more than 1,800 stories that aired during the spring of 2003, for objectivity and tone of the coverage. While their findings did reveal differences in coverage between US networks and Al Jazeera, the authors concluded that Al Jazeera's coverage was objective and generally neutral in tone, except when dealing with civilian casualties. The authors concluded that Al Jazeera's casualty coverage was generally negative and carried an antiAmerican tone. The Aday et al. study also examined differences in the use of visuals by embedded versus unilateral journalists. They found unilateral reporters used more visuals of civilian and Iraqi casualties. They concluded that the American networks provided a "sanitized" view of the war through predominantly embedded coverage.

Lynch (2007) examined the content of more than one thousand episodes of political talk shows from a five-year period on Al Jazeera. He found four broad topics - Palestine, Iraq, reform, and America - monopolized Al Jazeera's agenda. Lynch (2006) concluded that "negative images of the United States clearly predominated over positive images" (p. 218). 


\section{Images of Conflict and Explicit Violence}

Grabe, Zhou, and Barnett (2001) state that sensationalism "amuses, titillates, and entertains" (p. 637). In terms of content, sensationalism often refers to stories about crime, sex, disasters, accidents, public fear, fires, and violence (Adams, 1978; Ehrlich, 1996; Hofstetter \& Dozier, 1986; Vettehen, Nuijten, \& Beentjes, 2005). Sensational journalism has been characterized as content, which is emotional, attention grabbing, and commercialized (Grabe et al., 2001; Graber, 2001; Vettehen et al., 2005).

Like framing studies in general, many visual framing studies have focused on images of natural disasters, conflict, war, or terrorism. Conflict and violence are often listed as frames in deductive framing studies. Neuman, Just and Crigler (1992) found that conflict frames were the most common frames in US news. Wolfsfeld (2004) identified several possible reasons for researchers' interests in examining conflict coverage: (1) researchers find conflict coverage more interesting, (2) short-term event coverage is easier to examine, (3) conflict and disruption comprise normal TV news fare.

Several sensational news topics - sex, celebrity, crime - are still considered taboo subjects on pan-Arab media and receive limited coverage. However, it is assumed that images of conflict and violence regularly appear on pan-Arab newscasts. Furthermore, images of conflict and violence are of particular interest in the current study because they represent the sensational content elements that have received the most criticism from Westerners.

Scholars (Hallin, 1994; Shoemaker and Reese; 1996; Tuchman, 1978) have identified several factors - e.g. journalistic training, organizational structure, ideology, press freedom, cultural expectations - that shape media content. Audience preference is one factor that has been studied in the context of violent images in Arab Media.

Western news organizations, predominantly American networks, are particularly mindful of audience preferences. Those preferences tend to include less tolerance for violent images. A Pew Research Center survey (Kohut, 2004) found that $70 \%$ of Americans favored US media coverage of military action in Fallujah, Iraq that avoided showing gruesome images. Silcock, Schwalbe, and Keith (2008) note that western-based news decision-makers must wrestle with "showing the raw truth of harsh visuals while remaining compassionate and inoffensive to the audience" (p. 38). Scholars (Aday et al., 2005; Griffin, 2004; King and Lester, 2005; Silcock et al., 2008; Youssef, 2009; Zelizer, 2005) found that media outlets show few images of injury and death when covering war. Media Tenor (2003) conducted a cross-cultural framing analysis of coverage of the 2003 Iraq War on European, South African and American TV news, which included an analysis of visuals of American and Iraqi casualties. Their findings suggest American news reports avoided images of American casualties while presenting images of Iraqi casualties.

Decision-makers at Alhurra, and to a lesser extent BBC-Arabic, must not only consider the preferences of their Arab audience, but may also be influenced by the western preferences of visual decency, differences in 
standards of professionalism, and by additional pressures inherent in public diplomacy entities. As an international broadcaster seeking a large non-Arab audience, AJE may also be influenced by audience preferences that include use of less violent images. Therefore, Alhurra, BBC-Arabic, and AJE news coverage may rely on fewer visuals of conflict and violence.

Westerners, on the other hand, routinely criticize pan-Arab networks for a perceived bias toward sensational images of conflict and violence. Fahmy and Johnson (2007) surveyed Al Jazeera viewers about the network's perceived use of graphic visuals in its coverage of the Iraq War and Palestinian/Israeli conflict. The Arabic-language, web-based survey, revealed that $70 \%$ of respondents reported seeing graphic images of these conflicts on Al Jazeera, while $69.2 \%$ supported the network's decision to show these images. One respondent said:

Al Jazeera should show those video/images, because that's what realities/consequences of war and occupation or any civil unrest are. Selfcensorship is only a dis-service to the millions of viewers who depend on it for honest, un-sanitized and un-beautified news (Fahmy \& Johnson, 2007, p. 258).

The results of this study would seem to re-enforce Robertson's (2004) claim that Al Jazeera editors knew their audience expected to see graphic images. According to Wolfsfeld (2004), journalists react to the events they are covering and construct stories that are "politically acceptable to their readers" (p. 29). Kenney (1988) stated that audience expectation is a key consideration when a network is trying to build the largest audience possible. This knowledge is likely not lost on decision makers at Al Jazeera and Al Arabiya, which are locked in a battle for a share of the pan-Arab TV news audience. The result of this intensely competitiveness is what Hallin (1994) characterizes as "media populism".

Because they operate in different political, media, and cultural environments, it is expected that the networks included in the present study will differ in their visual framing of conflict and violent content. Therefore, it is hypothesized that:

H1: The Arab networks represented by the liberal commercial pattern of broadcasting will display more visuals of conflict than the networks representing the western-style.

H2: Violent imagery in the content of conflict coverage will be more explicit on the liberal commercial networks than on the western-style networks.

\section{Network Taxonomy}

\section{Method}

The current study - part of a larger research project (Bruce, 2012; 2014; 2016) - employed a content analysis, which examined visual images presented by five Arab media outlets - Al Jazeera, Al Jazeera English, Alhurra, BBC 
Arabic, and Al Arabiya. The five networks were chosen because they represent some of the most popular and controversial 24-hour news channels in the Arab world. Since its inception, Al Jazeera has been recognized as the flagship panArab satellite news channel. It is routinely ranked in Arab media surveys as the most watched pan-Arab news network (e.g. Telhami, 2011). Dajani (2007) noted that Al Arabiya became one of Al Jazeera's first serious rivals. There are also a number of foreign channels broadcasting into the Arab World. Two of the most recognized Arabic-language foreign channels are Alhurra and BBC Arabic. Finally, Al Jazeera English was chosen for inclusion in the study because of its relationship to the Arabic-language Al Jazeera.

After selection, the five networks were categorized into a two dimensional network taxonomy - western and liberal commercial. Ayish (2002) conceived the term liberal commercial to describe commercially competitive networks characterized by a high regard for professional standards, presented in westernstyled "critical and pluralistic views of society" (p. 142). For his study, Ayish assigned Al Jazeera to the liberal commercial pattern. For the present study, both Al Jazeera and Al Arabiya fit Ayish's definition of liberal commercial. These networks may not reflect the classical application of the term liberal media (e.g. journalistic freedom). However, in the context of Arab media both networks operate relatively free of editorial control and conform to the more liberal managerial approach described by Ayish.

The term western was originally chosen to classify the Western-based, public-diplomacy styled Alhurra and BBC Arabic networks since their mission is to provide a balanced, yet Western perspective, to Arab events. Al Jazeera English was included in the western dimension because of it's non-commercial status with a focus toward Arab public-diplomacy, charge for reaching an international audience including the United States, and attempts to separate editorial content from it's Arabic-language sister station. Additionally, Alhurra, BBC Arabic, and Al Jazeera English are considered non-commercial international broadcast networks. Since each of these networks relies on politically sensitive benefactors for operational funding, they have been grouped together to represent the western dimension.

\section{Sampling}

In order to construct the sample used in this study, programming on $\mathrm{Al}$ Jazeera, Al Arabiya, Al Jazeera English (AJE), and BBC Arabic was recorded between August 1, 2010, and June 15, 2011. Comparable newscasts from each of the networks were recorded either from broadcast television or online archives, depending on the availability of the content. Due to the extensive time span, 1,100 one-hour late evening newscasts were included in the sample frame. This sample frame consisted of everyday, routine news coverage in an attempt to lessen the influence of any one single event or story that would have dominated the sample. Although several major news stories occurred within the sample frame, only one story significantly dominated news coverage in a way that would have skewed normal news coverage. This exception was news 
coverage of the Arab Spring, which was covered heavily by international news networks. In order to combat these effects, newscasts between January 29 and February 20, 2011 (the height of the Arab Spring) were excluded from analysis. Between these dates, the networks were more likely to ignore the normal news cycle and instead air 24-hour breaking news style coverage. Therefore, the researchers conclude that the sample was representative of normal news productions styles, and excluded any coverage that was more dramatic than regular news.

Once the sample frame was constructed, a random date generator was employed in order to select specific dates for analysis in this study's sample. Three dates were selected, and coverage from all five networks resulted in 15 hours of news content, which contained 438 stories, broken down into 6,595 individual shots. The dates that were randomly selected were Wednesday, December 29, 2010, Thursday, January 27, 2011, and Tuesday, June 14, 2011.

Content was coded according to the type of story, the type of violence that was depicted (Fishman \& Marvin, 2003; Groshek, 2008), and the taxonomy of the news network, either liberal commercial or western. In order to assess the hypotheses presented in this study, the unit of analysis used was each individual image or shot. The definition of the unit of analysis was the same as the definition employed by Keith, Schwalbe, and Silcock (2009), who stated that a new unit of analysis would be delineated "each time the shot (subject) changed by video editing or, in the case of a pan, each time the subject changed" (p. 7). The term shot was liberally defined to include any image in the newscast (e.g. graphic, animation, studio, field report). These varieties of shots were included because frequency is a measure of visual framing.

\section{Coding Categories}

Each story was coded into one of 17 possible categories that have been outlined in previous studies (Groshek, 2008; Natarajan \& Xiaoming, 2003; Weaver, Porter \& Evans, 1984): (1) accidents/natural disasters, (2) agriculture, (3) business/economics, (4) crime/criminal justice/law and order, (5) ecology/ environment, (6) education, (7) health care, (8) military/national defence, (9) politics, (10) race/religion/culture, (11) social problems/services, (12) sports, (13) technology, (14) war/terrorism, (15) oddities; (16) undecided; and (17) tease.

The seventeen story types were then collapsed into four dummy coded variables: (1) politics/crime (politics, political unrest/war/terrorism, military/ national defence, crime/criminal justice/law); (2) business/technology (business/ economics, technology, education, agriculture, accidents/natural disasters); (3) humanitarian (humanitarian/social problems, health care, race/religion/culture, ecology/environment); (4) entertainment/other (oddities, sports, tease, undecided).

Depictions of conflict and violence as sensational content were explored in each shot that was included in the sample. For the purpose of this study, conflict or violence was defined as "disagreements between or among parties ... and needed to be obvious and clear from a casual viewing" (Groshek, 2008, p. 60). Klijn (2003). Using a modified definition of violence from the National Television Violence Study (1996, 1997, 1998), violence was defined as: 
any evidence of a credible threat of physical force or the actual use of such a force intended to physically harm or intimidate an animate being or a group of animate beings. Violence also includes certain depictions of physically or emotionally harmful consequences that occur as a result of the use of violent means against an animate being (or group of beings) (p. 132).

Fishman and Marvin (2003) note that this is a representative description of explicit violence found in most systematic studies of violent content.

The current study utilized a five category coding scheme for conflict and violence developed by Fishman and Marvin (2003) and refined by Groshek (2008). The categories are as follows: (1) No Conflict Frame, (2) Conflict Frame/Not Violent, (3) Conflict Frame/Dramatic Violence, (4) Conflict Frame/Latent Violence, and (5) Conflict Frame/Explicit Violence. The no conflict frame indicates the absence of conflict or violence in the image. The not violent frame contains images of conflict being handled in a peaceful manner, such as protest signs and marches. The dramatic violence frame includes images of violence that are "performed but not seriously intended" such as for sport or entertainment (Fishman \& Marvin, p. 34). Images containing latent violence do not show the "immediate application of direct physical force" but suggest "that such force could be applied" (Fishman \& Marvin, p. 34). Examples of latent violence include the presence of police, military personnel, and weapons. Finally, Fishman and Marvin refer to images of explicit violence as those showing either the direct application of, or consequences resulting from, violence which is "seriously intended and performed" (p. 34). Explicit violence includes images of firefights, damage to buildings or property, and injuries. The harmful aftermath of violence including the image of anguished victims or eyewitnesses was also included as explicit violence. Violence caused by non-manmade agents (natural disasters, animals, weather) was excluded.

\section{Coding and Inter-coder Reliability}

Before coding could begin, the researchers determined the parameters of each news story and also the in and out (beginning and end) points for each shot. Two coders were trained using a codebook developed for this study. Two separate pre-tests were conducted outside of the actual sample, in order to make sure that coders agreed on definitions and coding categories. Within these external samples, there was high reliability between the two coders. Once reliability was established outside of the final sample, coding within the full sample was completed. A primary coder analyzed the full sample, while the secondary coder examined $10 \%$ of the sample. Using Krippendorf's alpha, it was determined that the level of agreement for conflict and violence was 0.81 . Agreement for story and tease type was 0.90. Scores for all categories were above the acceptable level of 0.70 identified by Frey, Botan, and Kreps (2000). 


\section{Analysis Strategy}

Multi-level logistic regression models were used to analyze the hypotheses since the data from this sample was based on nested sources of variability. The unit of analysis, the shot, is nested within stories giving the data a multilevel, or hierarchical, structure. To ignore the structure of this data and collapse the data across the shots or to analyze the data without consideration for the multilevel structure could lead to an increase in either alpha (false positive) or beta (false negative) errors (Hox, 2002). The analysis controlled for story type (a dichotomous indicator of stories concerning politics, crime, conflict or not one of these), and shot length in seconds. The seventeen story types were collapsed into the following four dummy coded variables: (1) politics/crime (politics, political unrest/war/terrorism, military/national defense, crime/criminal justice/law); (2) business/technology (business/economics, technology, education, agriculture, accidents/natural disasters); (3) humanitarian (humanitarian/social problems, health care, race/religion/culture, ecology/environment); (4) entertainment/other (oddities, sports, tease, undecided). This was the case because the dependent variable did not vary (i.e., did not appear) for some story types. Control variables were included in order to rule out the influence of these extraneous factors. This is a conservative assessment, which results in more confidence that the control variables are not interfering with the focus variables under investigation.

\section{Results}

The first hypothesis predicted visuals of conflict would more likely appear in the newscasts of the liberal commercial networks than on the western networks. In the multi-level logistic regression model, the five-category dependent variable was collapsed into a dichotomous indicator of the presence (conflict/not violent, conflict/dramatic violence, conflict/latent violence, conflict/explicit violence) or absence (no conflict) of conflict. The network taxonomy of western styled networks (AJE, BBC Arabic, and Alhurra) and liberal commercial networks (Al Jazeera, and Al Arabiya) was dummy coded with western as the reference category (constant).

Table 1. Conflict Visuals by Network Taxonomy

\begin{tabular}{|l|c|c|c|c|}
\hline \multicolumn{1}{|c|}{ Variable } & $\boldsymbol{B}$ & $\boldsymbol{S . E .}$ & $\boldsymbol{Z}$ & $\boldsymbol{p}$ \\
\hline Constant & -1.21 & 0.26 & -4.60 & $<0.001$ \\
\hline Liberal Commercial & 0.57 & 0.29 & 1.96 & 0.050 \\
\hline Shot Length & -0.05 & 0.01 & -3.62 & $<0.001$ \\
\hline Story Type - Business/Technology & -3.28 & 0.51 & -6.50 & $<0.001$ \\
\hline Story Type - Humanitarian & -3.10 & 0.64 & -4.86 & $<0.001$ \\
\hline Story Type - Entertainment/Other & -1.55 & 0.32 & -4.87 & $<0.001$ \\
\hline
\end{tabular}

Note: Shots $(n=6,595)$. Stories $(n=438)$. Iterations $=300,000$, Burn-in $=5,000$. The variance of the constant across stories is $6.97\left(\chi^{2}=58.99, d f=1, p<0.001\right)$. 
Table 1 contains the results of the multi-level logistic regression model for H1. Shot length was a significant $(B=-0.05, S E=0.01, p<0.001)$ predictor of conflict. This means as shot length decreased the likelihood of conflict visuals increased. Similar results were found with the controls for story type. The business/technology, humanitarian, and entertainment/other story types were significant predictors of conflict visuals at the $p=0.001$ level. In other words, there is strong evidence that explicit violence was less likely for these story types when compared to the reference category (politics/crime story type).

Turning to the results of the hypothesis, the amount of conflict/violence in images differed significantly $(B=0.57, S E=0.29, p=0.05)$ for the liberal commercial networks when compared to the western reference (constant) category. This means visuals of conflict were significantly more likely to appear in the newscasts of the liberal commercial networks than on the western networks. H1 is supported.

Table 2. Visuals of Explicit Violence by Network Taxonomy

\begin{tabular}{|l|c|c|c|c|}
\hline \multicolumn{1}{|c|}{ Variable } & $\boldsymbol{B}$ & $\boldsymbol{S . \boldsymbol { E }}$. & $\boldsymbol{Z}$ & $\boldsymbol{p}$ \\
\hline Constant & -4.03 & 0.35 & -11.65 & $<0.001$ \\
\hline Liberal Commercial & 0.74 & 0.36 & 2.04 & 0.041 \\
\hline Shot Length & -2.80 & 0.66 & -4.24 & 0.960 \\
\hline Story Type - Business/Technology & -3.54 & 0.95 & -3.74 & $<0.001$ \\
\hline Story Type - Humanitarian & -1.66 & 0.41 & -4.07 & $<0.001$ \\
\hline Story Type - Entertainment/Other & -2.80 & 0.66 & -4.24 & $<0.001$ \\
\hline
\end{tabular}

Note: Shots $(n=6,595)$. Stories $(n=438)$. Iterations $=30,000$, Burn-in $=5,000$. The variance of the constant across stories is $2,142.83\left(\chi^{2}=28.96, d f=1, p<0.001\right)$.

$\mathrm{H} 2$ predicted the liberal commercial networks would utilize more images of explicit violence in conflict coverage than the western networks. Again a multi-level logistic regression model - with a dummy coded taxonomy featuring western networks as the reference category was utilized. The fivecategory indicator for conflict and violence was collapsed into a dichotomous indicator of the presence or absence of explicit violence. The control variable shot length was not a significant $(p=0.960)$ predictor of explicit violence. This means that shot length did not correlate to the use of explicitly violent images. As with H1, story type does appear to be a predictor of explicit violence. Each of the story type categories, business/technology, humanitarian, and entertainment/other story types were significant predictors of visuals of explicit violence in conflict coverage at the $p=0.001$ level. Once again, this reveals explicit violence was less likely for these story types when compared to the reference category (politics/crime story type).

Results from the hypothesis testing suggest that the level of explicit violence in images differed significantly $(B=0.74, S E=0.36, p=0.41)$ for the liberal commercial networks when compared to the western reference (constant) category. These findings reveal liberal commercial networks were significantly more likely to present images of explicit violence in conflict coverage than the western networks. $\mathrm{H} 2$ is also supported (Table 2). 
In general, the overwhelming majority of images on both western and liberal networks did not contain cues to conflict related visuals (Figure 1). This finding runs contrary to the popular belief that the majority of visuals aired on a daily basis by Arab networks, like Al Jazeera, are violent. However, significant differences in the use of conflict and violence do exist between the liberal and western networks. The liberal networks were significantly more likely than western networks to use conflict visuals. In addition, when they used conflict visuals, the liberal networks were also more likely than western networks to use images of explicit violence.

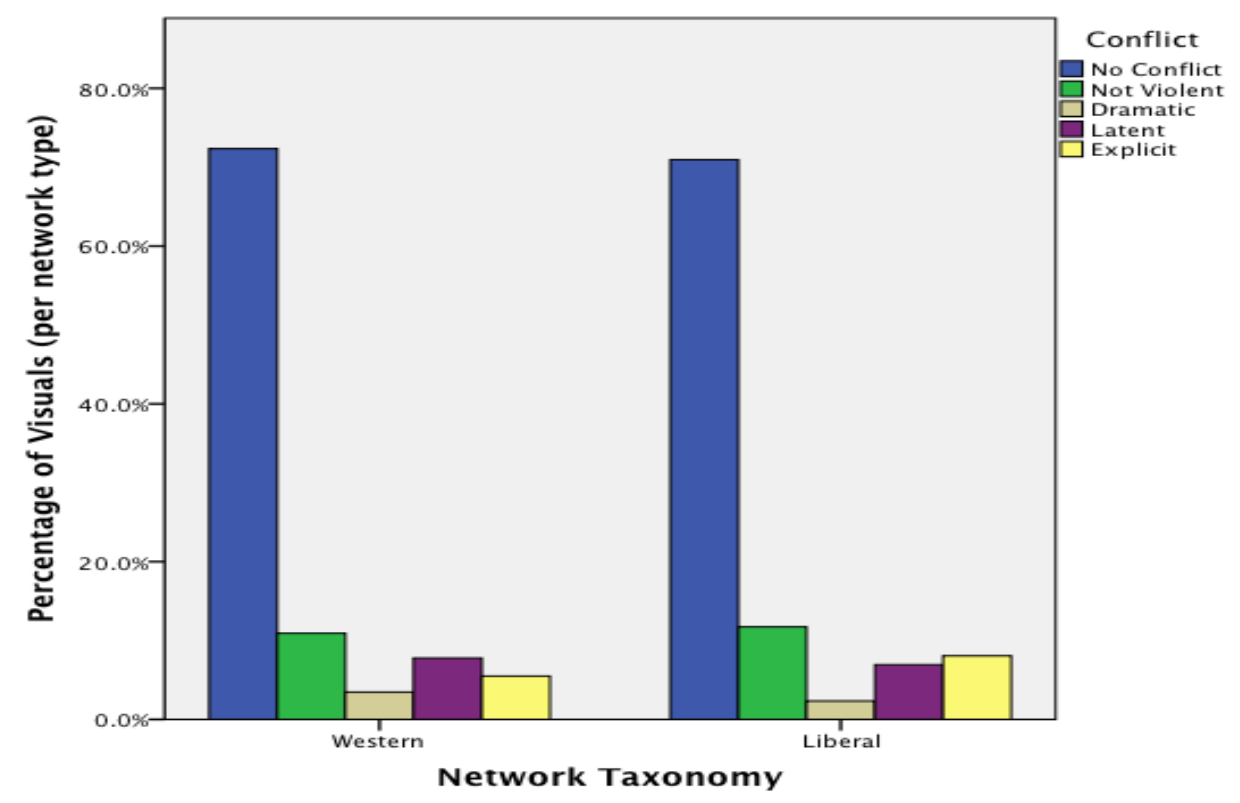

Figure 1. Frequency of Conflict and Violent Imagery by Network Taxonomy as Represented in $\mathrm{H} 1$.

\section{Discussion}

Most previous studies of conflict on Arab media have focused on crosscultural comparisons where cultural differences essentially ensure that media coverage differs. However, there have been few systematic comparisons of conflict visuals between pan-Arab satellite channels that are essentially staffed by Arabs with similar western journalistic training (Kraidy, 2012) and aimed at the same cultural audiences. Therefore, the differential use of conflict and violence in visuals was an important element of the current research design.

The liberal commercial networks identified in this content analysis - Al Jazeera and Al Arabiya - were more likely to utilize conflict visuals than the western networks - Alhurra, BBC Arabic, and Al Jazeera English - providing support for $\mathrm{H} 1$. The findings also revealed that conflict visuals were associated with a shorter shot length (quicker editing pace) and stories about crime, law, politics, civil unrest, war, and terrorism. In addition, conflict visuals on liberal 
commercial networks were more likely to depict explicit violence than on western networks $(\mathrm{H} 2)$.

Examples of these stories included ongoing US military activity in Iraq and Afghanistan, the Israeli/Palestinian conflict, Arab Spring uprisings, drug and crime operations. The images accompanying these stories vary greatly in terms of level of conflict. A June, 2011, attack on an Iraqi government compound in Baquba, provides an example of how the networks handled images of conflict and violence. Coverage on all the networks airing the story included explicit footage of the aftermath of the attack, including interior and exterior damage to the building. However, the number and focus of the images differed between the networks. For example, Al Jazeera English had a very short story about the attack with visuals that focused more on Iraqi government and US military officials discussing the attack on-site, than on more gruesome images of the attack. Arabic Al Jazeera's coverage was a bit longer, and included additional images of explicit violence, including images of a dead body, and a blood stained carpet. Finally, Al Arabiya's coverage included extensive footage of the aftermath of the violence, including a fast-paced photomontage, and minute and one-half long animated re-enactment of the attack. The animation appeared on a studio-sized monitor wall behind the anchor, as he described the attack.

The Baquba coverage reveals how Al Jazeera English presented a more sanitized view of the attack, while the liberal commercial networks presented a more graphic and sensational view Each network's visual presentation of the attack seems to reflect the network's sensitivities since each network's footage appeared to have come from the same single source. In addition, coverage of this violent event reveals why it is important to include all images (e.g. graphic, animation, photo, studio monitor) included in a newscast in order to accurately determine the level of conflict and violent images.

\section{Conclusions, Limitations, and Future Research}

The project was designed to measure the cumulative impact of images that are often repeated in a newscast, or over a series of newscasts. It is difficult to measure the overall level of conflict and violence on a newscast by only examining a few stories from each newscast. However, this cumulative visual approach results in some limitations.

Some would argue that the primary limitation present in this study is that there was no differentiation between the styles of visuals (e.g. graphics, animations, studio shots, and field shots). The authors have argued that including all visuals from a newscast is essential to determining framing through visual frequency. However, treating all types of visuals the same may not be the best approach since they may have varying impact on the audience. Future research could differentiate between these types of content by using a system like the one described by Doyle (1982), and Nimmo and Combs (1985). These studies used a visual prominence score to delineate types of visual content. 
Secondly, the sample size in this study prohibited researchers from having a truly generalizable, representative sample of visuals contained in content on pan-Arab satellite TV channels. The sample was limited to three days in order to make the several thousand distinct visuals manageable. Future research could increase the sample size in order to make the analysis generalizable.

Al Jazeera has been heavily criticized for presentation of graphic news visuals. This study produced results that corroborate the findings of a great deal of the previous work from cross-cultural comparisons of conflict visuals. The liberal networks framed more violent images of conflict while images on the western networks framed a more sanitized view of conflict. Despite obvious preferences for violent images, the overwhelming majority of visuals aired on pan-Arab networks are not as graphic as critics portend.

Liberal commercial Arab news networks - when they choose to depict conflict and violence - are framing their visual news content in a way that accentuates the explicitly violent aspects of news stories. This framing may lead audiences to shape their views and opinions about the conflicts that are taking place on the news (Chong \& Druckman, 2007). While on the surface this seems to be detrimental to audiences, several aspects of this framing must be discussed. First, most of the visuals that appeared in the sample did not contain any conflict or violence. Therefore, audiences may use this framing to determine that conflict and violence are less prevalent in the world than other visual images. Additionally, the framing of explicit violence that appears on liberal commercial networks may represent a more realistic view of violence, rather than the less violent frame that appears on western news networks, and glosses over the depiction of violence as it truly exists: as an explicit, terrible part of the human experience. This representation of a realistic view of violence seems to be acceptable to viewers of liberal commercial networks (Fahmy \& Johnson, 2007).

While the liberal networks were generally more violent, the visual differences did not appear to be as stark and pervasive as western government officials and media critics have let on over the past decade. The results present in this study support the idea that framing is present in all aspects of news production, however, future research should address the effects of this type of visual framing of violence on Arab and international audiences. The findings from this study suggest much of the recent criticism of pan-Arab satellite newscasts could be attributed to nothing more than hyper-, over-reaction.

\section{References}

Adams, W. C. (1978). Local public affairs content of TV news. Journalism \& Mass Communication Quarterly, 55(4), 690-695.

Aday, S., Livingston, S., \& Hebert, M. (2005). Embedding the truth: A cross-cultural analysis of objectivity and television coverage of the Iraq War. The Harvard International Journal of Press/Politics, 10(1), 3-21.

Ayish, M. (2002). Political communication on Arab world television: Evolving patterns. Political Communication, 19, 137-154. 
Barnett, B. \& Reynolds, A. (2009). Terrorism and the press: An uneasy relationship. New York: Peter Lang.

Barnhurst, K. G. (1994). Seeing the newspaper. New York: St. Martin's Press.

Barthes, R. (1978). Image, music, text. (S. Heath, Trans.). New York: Hill and Wang.

Bruce, M. D. (2012). Visual Framing on Arab satellite TV: Comparing the content and structure of Al Jazeera, Al Jazeera English, Al Arabiya, Alhurra and BBC Arabic Newscasts. (Unpublished doctoral dissertation). University of Oklahoma, Norman.

Bruce, M. D. (2014). Framing Arab Spring conflict: A visual analysis of coverage on five transnational Arab news channels. Journal of Middle East Media.

Bruce, M. D. (2016). Sensational pictures: An analysis of visual structure on five transnational Arab news channels. In J. V. Pavlik (Ed.), Digital Technology and the Future of Broadcasting: A Global Perspective. London: Routledge.

Chong, D. \& Druckman, J. N. (2007). Framing theory. Annual Review of Political Science, 10, 103-126.

Dajani, J. (2007). The Arab media revolution. Frontline World. Retrieved from http://www.pbs.org/frontlineworld/stories/newswar/war_arabmedia.html

Doyle, P. K. (1982). A descriptive study of bad-good news content in television newscasts. (Unpublished master's thesis). University of Tennessee, Knoxville.

Ehrlich, M. E. (1996). The journalism of outrageousness: Tabloid television news vs. investigative news. Journalism \& Mass Communication Monographs, 155, 1-24.

Entman, R. M. (1993). Framing: Toward clarification of a fractured paradigm. Journal of Communication, 43(4), 51-58.

Fahmy, S. (2004). Framing Visual News: The 9/11 attack and the war in Afghanistan in English - and Arabic - language newspapers. Paper presented at the meeting of International Communication Association, New Orleans, LA.

Fahmy, S. (2010). Contrasting visual frames of our times: A framing analysis of English- and Arabic-language press coverage of war and terrorism. The International Communication Gazette, 72, 695-717.

Fahmy, S. \& Kim, D. (2008). Picturing the Iraq war: Constructing the image of war in the British and US press. The International Communication Gazette, 70, 443-462.

Fahmy, S. \& Johnson, T. J. (2007). Show the truth and let the audience decide: A webbased survey showing support among viewers of al-Jazeera for use of graphic imagery. Journal of Broadcasting \& Electronic Media, 51, 245-264.

Fishman, J., \& Marvin, C. (2003). Portrayals of violence and group difference in newspaper photographs: Nationalism and media. Journal of Communication, 53(1), 32-44.

Frey, L., Botan, C., \& Kreps, G. (2000). Investigating communication: An introduction to research methods (2nd ed.). Needham Heights, MA: Allyn \& Bacon.

Gamson, W. A. \& Modigliani, A. (1989). Media discourse and public opinion on nuclear power: A constructionist approach. The American Journal of Sociology, 95(1), 1-37.

Ghanem, S. I. (1997). Filling in the tapestry: The second level of agenda setting. In M. E. McCombs, D. L. Shaw, \& D. H. Weaver (Eds.), Communication and Democracy (pp. 3-14). Mahwah: NJ: Lawrence Erlbaum Associates.

Gitlin, T. (1980). The whole world is watching: Mass media in the making and unmaking of the new left. Berkley, CA: University of California Press.

Grabe, M. E., Zhou, S., \& Barnett, B. (2001). Explicating sensationalism in television news: Content and the bells and whistles of form. Journal of Broadcasting \& Electronic Media, 45, 635-655. 
Graber, D. A. (2001). Processing politics: Learning from television in the Internet age. Chicago: The University of Chicago Press.

Graber, D. A. (1987). Television news without pictures? Critical Studies in Mass Communication, 4, 74-87.

Griffin, M. (2004). Picturing America's 'war on terrorism' in Afghanistan and Iraq: Photographic motifs as news frames. Journalism, 5, 381-402.

Groshek, J. (2008). Homogenous agendas, disparate frames: CNN and CNN International coverage online. Journal of Broadcasting \& Electronic Media, 52, 52-68.

Hafez, K. (2001). Mass media in the Middle East: Patterns of political and societal change. In K. Hafez (Ed.), Mass media, politics \& society in the Middle East (pp. 1-20). Cresskill, NJ: Hampton Press.

Hall, S. (1973). The determinations of news photographs. In S. Cohen \& J. Young (Eds.), The manufacture of news (pp. 176-190). Beverly Hills, CA: Sage Publications.

Hallin, D. C. (1994). We keep America on top of the world: Television journalism and the public sphere. London: Routledge.

Herman, E. S., \& Chomsky, N. (1988). Manufacturing consent: The political economy of mass media. New York: Pantheon Books.

Hofstetter, C. R., \& Dozier, D. M. (1986). Useful news, sensational news: Quality, sensationalism and local TV news. Journalism Quarterly, 63(4), 815-820.

Hox, J. (2002). Multilevel analysis: Techniques and applications. Mahwah, NJ: Lawrence Erlbaum.

Jasperson, A. E., Shah, D. V., Watts, M. D., Faber, R. J., \& Fan, D. P. (1998). Framing and the public agenda: Media effects on the importance of the federal budget deficit. Political Communication, 15, 205-224.

Jasperson, A. E., \& El-Kikhia, M. O. (2003). CNN and al Jazeera's media coverage of America's War in Afghanistan. In K. Hafez (Ed.), Framing Terrorism (pp. 133132). New York: Routledge.

Keith, S., Schwalbe, C. B., \& Silcock, B. W. (2009). Visualizing cross-media coverage: Picturing war across platforms during the U.S.-Led Invasion of Iraq. Atlantic Journal of Communication, 17, 1-18.

Kenney, K. (1988). Ideology and press photographs: A framework for analysis. Paper presented to the meeting of Association for Education in Journalism and Mass Communication, Portland, Oregon.

Kepplinger, H. M. (1991). The impact of presentation techniques: Theoretical aspects empirical findings. In F. Biocca (Ed.), Television and political advertising: psychological processes (pp. 173-194). Hillsdale, NJ: Lawrence Erlbaum Associates, Inc.

King, C. \& Lester, P. M. (2005). Photographic coverage during the Persian Gulf and Iraqi wars in three U.S. newspapers. Journalism \& Mass Communication Quarterly, 82, 623-637.

Klijn, M. E. (2003). Attention-getting and comprehension-raising attributes in visuals in Dutch and American, public and private television news about violence. Journal of Broadcasting \& Electronic Media, 47, 124-144.

Kohut, A. (2004). After Falluja public support for war steady, but Bush job ratings slip. Washington, DC: Pew Research Center for the People \& the Press. Retrieved from http://people-press.org/http://people-press.org/files/legacy$\mathrm{pdf} / 210 . \mathrm{pdf}$

Kraidy, M. M. (2012). The rise of transnational media systems: Implications of panArab media for comparative research. In D. C. Hallin \& P. Mancini (Eds.), 
Comparing media systems beyond the Western world (pp. 177-200). New York: Cambridge University Press.

Lynch, M. (2006). Anti-Americanism in the Arab world. In P. Katzenstein \& R. Keohane (Eds.), Anti-Americanism in world politics (pp. 196-224).

Lynch, M. (2007). Arab arguments: Talk shows and the new Arab public sphere. In P. Seib (Ed.), New media and the new Middle East (pp. 101-118). Hampshire, England: Palgrave Macmillan.

Matthes, J. (2009). What's in a frame? A content analysis of media framing studies in the world's leading journals. Journalism \& Mass Communication Quarterly, 86(2), 349-367.

McLuhan, M., \& Fiore, Q. (1967). The medium is the message: An inventory of effects. New York: Bantam Books.

Media Tenor. (2003). War coverage and cover-up: TV reports on the War in Iraq. Retrieved from http://www.mediatenor.com/Iraq/sld001.htm.

Messaris, P. (1992). Visual 'manipulation': Visual means of affecting response to images. Communication, 13, 181-195.

Messaris, P. (1994). Visual "literacy": Image, mind, and reality. Boulder, CO: Westview Press.

Messaris, P., \& Abraham, L. (2001). The role of images in framing news stories. In S. D. Reese, O. H. J. Gandy, \& A. E. Grant (Eds.), Framing public life: Perspectives on media and our understanding of the social world (pp. 215-226). Mahwah, NJ: Lawrence Erlbaum Associates.

Natarajan, K., \& Xiaoming, H. (2003). An Asian voice? A comparative study of Channel News Asia and CNN. Journal of Communication, 53, 300-314.

National Television Violence Study: 1994-1995 - Scientific papers. (1996). California: Mediascope, Inc.

National Television Violence Study (Vol. 1). (1997). Newbury Park, CA: Sage.

National Television Violence Study (Vol. 2). (1998). Newbury Park, CA: Sage.

Neuman, W. R., Just, M. R., \& Crigler, A. N. (1992). Common Knowledge. Chicago: University of Chicago Press.

Nimmo, D., \& Combs, J. E. (1985). Nightly horrors: Crisis coverage by television network news. Knoxville, TN: The University of Tennessee Press.

Norris, P., Kern, M., \& Just, M. (2003). Framing terrorism. Framing terrorism: The news media, the government, and the public (pp. 3-23). New York: Routledge.

Pan, Z. \& Kosicki, G. M. (1993). Framing analysis: An approach to news discourse. Political Communication, 10, 55-75.

Pfau, M., Haigh, M., Shannon, T., Tones, T., Mercurio, D., Williams, R., Binstock, B., Diaz, C., Dillard, C., Browne, M., Elder, C., Reed, S., Eggers, A., \& Melendez, J. (2008). The influence of television news depictions of the images of war on viewers. Journal of Broadcasting \& Electronic Media, 52, 303-322.

Robertson, L. (2004). Images of war. American Journalism Review, October/ November. Retrieved from http://www.ajr.org/Article.asp?id=3759

Semetko, H. A., \& Valkenburg, P. M. (2000). Framing European politics: A content analysis of press and television news. Journal of Communication, 50(2), 93-108.

Shoemaker, P. \& Reese, S. (1996). Mediating the message: Theories of influence on mass media content. ( $\left.2^{\text {nd }} E d.\right)$. Hoboken, NJ: John Wiley \& Sons, Inc.

Silcock, B. W., Schwalbe, C. B., \& Keith, S. (2008). "Secret" casualties: Images of injury and death in the iraq war across media platforms. Journal of Mass Media Ethics, 23, 36-50.

Telhami, S. (2011). 2011 Annual Arab public opinion survey. Retrieved from http://www.sadat.umd.edu/ViewsArabs_Oct11_graphs\%20FINAL.ppt 
Tirohl, B. (2000). The photo-journalist and the changing news image. New Media \& Society, 2(3), 335-352.

Tuchman, G. (1978). Making news: A study in the construction of reality. New York: The Free Press.

Vettehen, P. H., Nuijten, K., \& Beentjes, J. (2005). News in an age of competition: The case of sensationalism in Dutch television news, 1995-2001. Journal of Broadcasting \& Electronic Media, 49, 282-295.

Vujakovic, P. (1998). Reading between the lines: using news media materials for geography. Journal of Geography in Higher Education, 22, 145-155.

Weaver, J., Porter, C., \& Evans, M. (1984). Patterns in foreign news coverage on U.S. network TV: A 10-year analysis. Journalism Quarterly, 61, 356-363.

Wolfsfeld, G. (2004). Media and the path to peace. Cambridge, UK: Cambridge University Press.

Woollacott, J. (1982). Messages and meanings. In M. Gurevitch, T. Bennett, J. Curran, \& J. Wollacott (Eds.), Culture, society and the media (pp. 91-111). New York: Routledge.

Youssef, M. (2009). Their word against ours: News discourse of the 2003 Gulf War civilian causalities in CNN and Aljazeera. Global Media Journal, 4(2), 13-24. Retrieved from http://globalmedia.emu.edu.tr/fall2009/issues/2 Mervat_Yous sef_pp13_24.pdf

Zelizer, B. (2005). Death in wartime: Photographs and the "other war" in Afghanistan. The Harvard International Journal of Press/Politics, 10(3), 26-55. 
